\title{
Introduction: (re)thinking migration memories and diasporic practices from the perspective of the African continent
}

\author{
Francesca Declich and Marie Rodet
}

\begin{abstract}
Almost every day, and especially during summer, European countries bordering the Mediterranean are bombarded with radio news about boats full of migrants from Africa who have sailed from the coasts of Libya or Morocco and are seeking to reach Europe. They may be escaping from wars or persecution, looking for jobs or simply in search of a better life, but they are all portrayed as part of the entire African population that is moving towards Europe, as if this were a relentless planned invasion. European media rarely convey the information that migration within the African continent is actually the most prominent migration pattern experienced by African populations. According to the UN International Migrant Stock Report for 2015, of the 244 million international migrants worldwide, an estimated 20.65 million are from Africa, 78 per cent of whom migrate within the continent (UN DESA 2015). African migration beyond Africa's borders therefore remains marginal in volume, as it involves about 4.5 million Africans out of a total population of more than 1.2 billion. Yet with the current European obsession with African migration, research material in the last two decades has mainly focused on population movements towards developed countries, and relatively few approaches have looked at the African continent itself.
\end{abstract}

There are a number of possible reasons for this neglect. During the last decade, the widespread use of the concept of transnationalism (Vertovec 1999; Schiller and Çağlar 2009; Glick Schiller et al. 1992) has given rise to much knowledge production about African migrations financed and developed with the very deliberate aim of implementing policies about African migrants coming to Europe. This research has therefore overlooked many aspects of the migratory processes on the African continent; the exception has been the North African part of those itineraries, which has drawn much attention since the EU's border externalization process began in 2003. Meanwhile, transnational perspectives from below have revisited migration from the micro-perspective of migrants' own experiences, which are often at odds with policies of control and domination by global capital and the

\footnotetext{
Francesca Declich is Associate Professor at the University of Urbino Carlo Bo. She has carried out long-term ethnographic fieldwork and archival research in Somalia, Tanzania and Mozambique and with Somali refugees in East Africa and the US. Her latest edited book is Translocal Connections across the Indian Ocean: Swahili-speaking networks on the move (Brill, 2018). Email: francesca.declich@uniurb.it

Marie Rodet is a senior lecturer in the History of Africa at SOAS, University of London. Her research interests lie in the fields of modern migration history, gender studies and the history of slavery in Francophone West Africa. She is the author of Les migrantes ignorées du Haut-Sénégal (1900-1946) (Karthala, 2009) and the co-editor (with Elodie Razy) of Children on the Move in Africa: past and present experiences of migration (James Currey, 2016). Email: mr28@soas.ac.uk
}

(C) International African Institute 2018 
nation state (Smith and Guarnizo 1998). However, transnational processes remain linked to and grounded in the boundaries of the nation state (Smith 2003). Furthermore, the transnational endeavour is mainly presentist, and often fails to examine the impact on specific communities of their long history and memories of migration. Long- and short-distance, forced and willing migrations within and out of Africa - not only via the Mediterranean and the Atlantic, but also across the Indian Ocean - occurred well before the construction of nation states worldwide, and followed endogenous social developments resulting from both internal and external dynamics (Declich 2016; Kaarsholm 2012; Freitag and Von Oppen 2010). Population movements of hunters, pastoralists, farmers, traders and sailors, as well as mobilities due to human or natural disasters, are reported in the mythical narrations of many African communities. Nation states served merely to impose new legal frameworks upon people who had been travelling for centuries (Ibrahim 2010: 7).

Anthropologists and historians of Africa have very often encountered migratory phenomena in their research. Yet, in many early studies, migration was seen as incidental in otherwise stable and non-mobile societies. Displaced people, as highlighted by Liisa Malkki, were not traditionally considered a proper field topic for anthropologists; this included so-called refugees, who, by virtue of their displacement, could not be identified with a place, a country or a nation. The idea that territories were to be enclosed in borders, people were to settle in one of those territories, and they had to identify with such nations in Africa, was sanctioned at the Berlin Conference (1884-85). It is this enforced idea of nation - the national order of things, as Malkki called it - that makes displacement a problem and 'emplacement' a normality (Malkki 1995: 516). More recently, the African continent has been regarded as a place where migration was always a legitimate way of life (Turton and Allen 1996; Turton 2003; Schlee 1989). This perspective led some scholars to see Africans, above all, as mobile and deeply embedded in so-called 'cultures of migration' (Hahn and Klute 2007), creating a tendency to present these migratory processes as 'deterritorialized'. Yet this trend, in a different way, considers African societies as following set patterns, and ultimately obscures historical changes.

How can we reinstate migration within the continent as a central focus of research in African studies, beyond the usual transnational approach that is oriented towards the present? How crucial does the study of migration memories appear in such an endeavour? Looking at memories of migration offers a longue durée perspective from below on the formation of specific communities in Africa. It invites us to examine alternatives to narratives of past and present political hegemonies, while simultaneously exposing them to criticism. But it also offers a means to explore the complex links, across time and space, between global politics and intimacy; to examine how individual, 'anonymous', 'subaltern' memories are both transmitted and permeated by global politics; and to discover how they sometimes become collective (Halbwachs 1992), and thus create specific 'memory milieus' that can be activated as paths of resilience and mobilization against national and global hegemonic memories (Rodet and Reinprecht 2013). 
Shared memories constructed around mobility and migration play a crucial role in many African societies, especially in structuring social stratifications. ${ }^{1}$ In certain regions, such as southern Somalia or northern Kenya, the present structure of authority is the result of successive waves of migration and adoption among clans, which have resulted in the creation of confederations of groups with different origins (Schlee 1989; Declich 2002; Helander 1997). In such situations, oral narratives about the past, including the construction of genealogies, become forms of negotiated shared memories, crucial to the later recognition of the group's identity and authority (Cerulli 1959). Memories of mobility and settlement have therefore been used to make claims to authority, and potentially have the power to cause tensions between firstcomers and subsequent settlers, especially in today's context of increasing legal framing of mobility and settlement (Casentini, this issue).

Until the 1990s, the topic of 'memory and migration' was studied mostly within the framework of Anglo-American diaspora studies, with a focus on the African diaspora in North America and its identity. We have also seen the development of memory studies, initially closely linked to the study of the Shoah or Holocaust, but progressively reaching all spheres of the social sciences, particularly those related to studies of trauma. Those discussions reached European shores in the early 2000 s with the emergence of public debates on the legacies of slavery and colonization and the revisiting of the history of black presence in Europe. Migration within Africa has thus received scarce attention, and the term 'diaspora' is still little used, with a few exceptions (Alpers 2001b; Byfield 2000; Zeleza 2005: 44 7; 2010; Rudolf 2016). Is this because of a blind spot in the scholarship, or because the term diaspora does not seem relevant in an African context?

The concept of diaspora comes from diaspeirein (dia meaning 'across' and sperein 'seeding or spreading seeds') - the Greek designation for spreading out. Originally the concept referred in particular to the dispersal of the Jewish community. The meaning has been increasingly extended to the settlement of any community outside its homeland. Yet, even in the North American context, the idea of an African diaspora is not uncontested terrain and remains highly debated in conceptual terms, especially as a distinction is often made between the forced migration of African enslaved populations to the New World and today's 'willing migration' from Africa. While Africa has been increasingly recognized as part of the 'Black Atlantic' (Gilroy 1995), the entire issue of the African diasporic formation is still primarily focused on the Atlantic experience; the literature therefore tends to overlook any other diasporic experiences and practices on the African continent outside the slave trades (Schramm 2008). Where the diasporic approach is used in studies of migration within the African continent, it is still mostly applied to the history of slavery and related forced migration, especially from sub-Saharan Africa to North Africa, ${ }^{2}$ but also across the Indian Ocean. ${ }^{3}$ Yet, as stressed by

\footnotetext{
${ }^{1}$ For example, much of the literature about matrilineal societies has described dynamics created within generations of brothers, who, as they did not enter into the ruling lineages, migrated away from their original groups, taking with them a number of relatives to create their own lineage (Alpers 1972). Such processes can also arise from a combination of factors, including the search for water for pasturing animals, the search for better agricultural land, internal dissension, religious purposes, and so on.

${ }^{2}$ See, for example, El Hamel (2014).

${ }^{3}$ See, for instance, Alpers (2001a; 2000; 2003).
} 
Knörr and Kohl (2016), 'diasporic entanglements' on the continent are extremely diverse and multifaceted.

If we do not integrate overlapping diasporic experiences of African populations within the continent into the global African diasporic experience, says Alpers, we risk overlooking significant popular, non-elite traditions that link dispersed communities of Africans across the continent and that interrogate the experience of being both African and 'different' in Africa (Alpers 2001b). Memories can be performed in many different ways, and not only in historical narrative forms. Cultural features such as music, dance, religious expressions or healers' discourses may reveal alternative and subaltern memories of displacement in and outside the continent (Alpers 2000; Shaw 2002). According to this perspective, memories of intra- and extra-continental migrations are crucially linked and thus form multiple diasporas, producing overlapping diasporic practices and affiliations (Schramm 2008).

This special issue probes the relevance of using analytical terms such as diaspora, transnationalism and translocality to explore issues of memories and migration on the African continent and beyond.

We are aware that such concepts are often applied to socio-historical contexts where they can take on concrete political meanings. The term diaspora, for example, implies the idea of an original home where people may have the right to return and claim back land. Such claims, when recognized, can entail the emergence of political identities based on ethno-cultural features and can subsequently help grant specific rights to land tenure in the context of nation states. ${ }^{4}$ For Jana Evans Braziel and Anita Mannur (2003), the idea of diaspora - but also transnationalism and translocality - evokes the historicity of nations and nationalism, and leads us to re-think new forms of relationships between citizens and nation states.

In this special issue, three articles (Casentini, Nair, and Rodet and County) address and study overlapping waves of diasporic peoples, whose successive and cumulative migratory experiences over several generations give rise to specific communities in a cultural context where they are addressed as foreigners. Their position creates specific difficulties, but also allows them to stay and to assume the role of outsiders, not only in their host society but also in their 'home society' when they return (Rodet and County). In other cases, they use their 'foreign' origin to play the role of regulators or intermediaries in the host society and local culture (Casentini). In most cases, the construction of memories and/or historical narratives of their homeland have played a crucial role in their survival as legitimately settled groups, but these can also be simultaneously contested (Casentini, Nair, and Rodet and County).

So what role have memories played in building such diverse communities? Mourre invites us to review the complex relationships between memories and imaginaries in Africa by considering the recent massive exodus of young people in dramatic conditions from Senegal to Europe - which often draws parallels in Senegal with the migratory experience of the tirailleurs (African infantry soldiers recruited in colonial French Africa during the nineteenth and twentieth centuries).

\footnotetext{
${ }^{4}$ See, for instance, the discussion about diasporas of indigenous groups, such as the Mapuche in Chile (Baeza 2013).
} 
Memories of migration do not work in a vacuum: they interact with a background of related imaginaries, which feed the re-elaboration of memories. This is especially true for migrants whose travels are often prompted by an image of what they will find, mixed with inner desires of individual realization and projection about what they would like to find in the country of migration. Memories are not simply detached from other aspects of people's lives. Rodet and Reinprecht (2013: 10) suggest studying the milieus rather than the places of memories, in order to widen the analysis of cultural context and the spaces that prompt the production of memories. Memories function according to certain rhetorical and narrative rules that are also part of a certain milieu, and that are constitutive of different memoryscapes (Argenti and Röschenthaler 2006). Memories are not only produced but also need to be communicated, shared and performed, and are thus reproduced as well as renegotiated. Declich's article describes how Somali memories of forced migration in Tanzania have been framed in the form of mythical histories and communicated through ritual networks. When ritual networks decline, other media such as written material and videos become more important means of communication; certain memories may thus lose importance as migratory imaginaries change. In Mourre's case study, the re-memorization of the history of migration by Senegalese tirailleurs becomes part of youth imagery through films and other means of communication.

This last point prompts us to question the conditions under which memories of migration are constituted as collective memories. For example, Nair's article analyses how the specific migration history of the Mehta family has been embedded in distinct sites of memory; it has thus become the collective memory of Uganda's Indian community across different spaces, through the creation of overlapping collective identities and memory milieus. What is less known as yet is the extent to which migrants and their descendants have a say in such (re)constructions, and how they exert their agency in the constitution of collective memories. Rodet and County demonstrate how long-standing Malian diasporic communities along the railway from Mali to Senegal contested top-down ascribed national identity and behaviours at the time of independence by maintaining the memories and practices of mobility between both countries, despite the closure of the border. Thus, translocal memories of migration have strongly contested the nation's central place in postcolonial Africa. As Casentini states, the Zongo people in Ghana have constantly used their memories of migration and mobility to create a specific urban and social fabric, carving out opportunities in the local society away from the central power.

It is difficult to assess whether lived experiences of different types of migration, such as forced or economic migration, may produce distinct collective narrations and memories. Rodet and County's article suggests that forced or unexpected migrations might produce forms of nostalgia linked to their suddenness and the unexpected life changes they entail. In Casentini's study, veterans' shared memories are shown to be quite uniform as they helped the people of the Zongo to avoid being expelled. For Declich, experiences of forced migration as an escape from slavery have produced extremely cohesive narratives of flight from captivity within the Zigula groups, although the early inhabitants of the Gosha area came in successive historical waves and did not all escape in one group. Yet, narrative strategies within the framework of the same general story also reveal power negotiations and agency in the production of collective memories. As Declich 
further explains, new versions of the early history of forced migration or escape from slavery now include new genealogies of families seeking visibility.

In turn, we also need to explore how these collective narratives may inform migrants' lives. Rodet and County's article shows that the collective memories of the cultural continuum along the railway continued to inform diasporic practices that could not be stopped simply by closing the border. Casentini further describes how collective memories of migration still have a crucial role in fostering the identity of the Zongo group, preserving and distinguishing themselves from the other populations inhabiting slums and deprived areas. For Declich, memories of early forced migration of escape from slavery have been crucial in pushing the authorities and the people of the rural district of Handeni to recognize Somali Zigula. Nowadays, young adults prefer to present themselves not as refugees but as Tanzanians, in order to have easier access to jobs.

While collective memories of migration still inform certain communities and their imaginaries, other aspects of those communities' pasts are simultaneously being silenced. According to Casentini, re-reading the past works to silence the scarce political authority held within the Zongo. Indeed, the shared narrative of autonomy and extreme freedom also reflects their lack of land rights and their liminal position as strangers or migrants in a society of settled people.

In some instances migration has produced specific forms of group consciousness and endogenous narratives, which nevertheless remain far from stable. Everyday mobility as part of larger travel patterns can also become part of a people's selfnarration, resulting in group consciousness narratives. For example, in Casentini's case study, Hausa people often speak about themselves as cultural bridges between their places of origin and the host societies where they have settled. In this context, these migrants' contributions, as well as their connection to their original country, can become particularly important in the political discourses of some African societies. Nair further discusses the extent to which narratives of trauma have generated specific forms of generational consciousness linked to expulsion, creating a need for sites of memory to be constructed in order to embed these memories in a larger group consciousness. Beyond group consciousness, memories and narratives of migration also help reinforce the ethnicization of some communities. In Tanzania (see Declich), Somali Zigula escaping slavery claimed a shared ethnicity in order to legitimize their migration to Tanzania and to facilitate their acceptance in the rural areas of Handeni. Long and cumulative histories of migration and corresponding memories can serve to reinforce top-down processes of ethnicization. However, for Nair, although Ugandan Indians may appear to be a clear ethnic group, successive waves of Indian migration into Uganda, combined with the traumatic history of expulsion, mean that the identity of Ugandan Indians has been constantly transformed over the past hundred years. 'Ugandan Indian' is therefore neither a fixed identity nor a unified community.

Finally, we still know too little about the extent to which the gender roles present in memories of migration have been (re)negotiated, and for what purposes. As explained by Declich, memories of an early escape from slavery in southern Somalia were clearly gendered. During different phases of migration and in specific social contexts, the mythical leaders of the migrating groups have been represented as men or women, depending on the social composition and the interests of the audiences to whom such memories are addressed. 
Memories of migration within the African continent are articulated locally but also follow external dynamics, depending on the situation and the needs of those (re)producing them. They are in the hands of the people who migrate and their descendants and may be used, in different situations, to achieve legitimacy (Casentini) or to create group identities (Nair, and Rodet and County). They may also, in specific circumstances, become founding ideologies and imaginaries for those communities (Declich and Mourre). The production of memories of migration may further help certain migrants and their descendants to reclaim agency in their own life trajectory. Yet memories of migration may also be a factor in reproducing marginalization. These memories are multiple and can be articulated across diverse social and cultural milieus. They are the products of both marginalized and hegemonic communities. Most articles in this special issue examine the meanings of certain memories and memory milieus for migrants and their descendants. In this way, these articles decentre the usual trends of knowledge production about African migrations. Such knowledge is mostly produced in the transnational analytical framework of African migration towards Europe and thus is constructed from outside; it labels and classifies 'African migrants' and thus essentializes them as part of a homogeneous group of people, pushed or pulled by externally determined forces. It includes them in specific legal frameworks and tends to deny them agency. Zetter (1991) shows that labelling people as 'refugees' is one of the processes that bureaucratizes their status and restricts them to a range of specific options.

For these reasons, retrieving and studying memories of migration - including specific features and artefacts such as music, dance, healers' discourse and rituals - are crucial, as they examine the ways in which people (both women and men) construct their own reality of movement, as opposed to being constructed. Such studies also highlight that geographical movements in search of better resources and livelihoods have been common within Africa, and that they often underlie processes of social stratification, but not necessarily of exclusion. ${ }^{5}$

\section{References}

Alpers, E. A. (1972) 'Towards a history of the expansion of Islam in East Africa: the matrilineal peoples of the southern interior' in I. N. Kimambo and T. O. Tanger (eds), The Historical Study of African Religions. Berkeley and Los Angeles CA: University of California Press.

Alpers, E. A. (2000) 'Recollecting Africa: diasporic memory in the Indian Ocean world', African Studies Review 43 (1): 83-99.

Alpers, E. A. (2001a) 'Becoming "Mozambique": diaspora and identity in Mauritius' in V. Teelock and E. Alpers (eds), History, Memory and Identity. Port Louis, Mauritius: Nelson Mandela Centre for African Culture, University of Mauritius.

Alpers, E. A. (2001b) Defining the African Diaspora. Los Angeles CA: Manuscript.

\footnotetext{
${ }^{5}$ The co-authors wrote this introduction as follows: Declich paragraphs 1, 2, 3, 5, 8, 10, 14, 16, 17 and 19; Rodet paragraphs 4, 6, 7, 9, 11, 12, 13, 15, 18 and 20. Both revised all paragraphs.
} 
Alpers, E. A. (2003) 'The African diaspora in the Indian Ocean: a comparative perspective' in S. de Silva Jayasuriya and R. Pankhurst (eds), The African Diaspora in the Indian Ocean. Trenton NJ: Africa World Press.

Argenti, N. and U. Röschenthaler (2006) 'Introduction. Between Cameroon and Cuba: youth, slave trades and translocal memoryscapes', Social Anthropology 14 (1): 33-47.

Baeza, E. A. (2013) 'Migración Mapuche y continuidad colonial' in H. N. Moreno et al. Historia, colonialismo y resistencia desde el país Mapuche. Temuco: Ediciones Comunidad de Historia Mapuche.

Braziel, J. E. and A. Mannur (2003) 'Nation, migration, globalization: points of contention in diaspora studies' in J. E. Braziel and A. Mannur (eds), Theorizing Diaspora. Oxford: Blackwell Publishing.

Byfield, J. (2000) 'Introduction: rethinking the African diaspora', African Studies Review 43 (1): 1-9.

Cerulli, E. (1959) Somalia. Diritto ed etnografia, linguistica, come viveva una tribù Hawiyya. Vol. 2. Rome: Istituto Poligrafico dello Stato.

Declich, F. (2002) I Bantu della Somalia. Etnogenesi e rituali mviko. Milan: Franco Angeli.

Declich, F. (2016) 'Migrations, women and kinship networks in the western Indian Ocean: a comparative perspective' in M. Grassi and T. Ferreira (eds), Mobility and Family in Transnational Space. Cambridge: Cambridge Scholars Publishing.

Freitag, U. and A. Von Oppen (2010) 'Introduction. "Translocality": an approach to connection and transfer in regional studies' in U. Freitag and A. Von Oppen (eds), Translocality: the study of globalising phenomena of a southern perspective. Leiden: Brill.

Gilroy, P. (1995) The Black Atlantic Modernity and Double-Consciousness. Harvard MA: Harvard University Press.

Glick Schiller, N., L. Basch and C. Blanc-Szanton (1992) 'Transnationalism: a new analytic framework for understanding migration', Annals of the New York Academy of Sciences 645: 1-24.

Hahn, H. P. and G. Klute (2007) Cultures of Migration: African perspectives. Munster: LIT Verlag.

Halbwachs, M. (1992) On Collective Memory. Chicago IL: University of Chicago Press.

Helander, B. (1997) 'Clanship, kinship and community among the Rahanweyn: a model for other Somalis?' in H. M. Adam and F. Richard (eds), Mending Rips in the Sky: options for Somali communities in the 21st century. Lawrenceville NJ: Red Sea Press.

El Hamel, C. (2014) Black Morocco: a history of slavery, race, and Islam. New York NY: Cambridge University Press.

Ibrahim, A. (2010) 'Introduction: concepts, practice and policies of international migration in Africa' in A. A. Yusuf (ed.), African Yearbook of International Law. The Hague: African Foundation for International Law.

Kaarsholm, P. (2012) 'Diaspora or transnational citizens ? Indian Ocean networks and changing multiculturalisms in South Africa', Social Dynamics 38 (September): 454-66.

Knörr, J. and C. Kohl (eds) (2016) The Upper Guinea Coast in Global Perspective. Oxford: Berghahn Books. 
Malkki, L. (1995) 'Refugees and exile: from "refugee studies" to the national order of things', Annual Review of Anthropology 24 (1): 493-523.

Rodet, M. and C. Reinprecht (2013) 'Mémoires et migrations en Afrique de l'ouest et en France', Revue Européenne des Migrations Internationales 29 (1): $7-22$.

Rudolf, M. (2016) 'Identity beyond ID: diaspora within the nation' in J. Knörr and C. Kohl (eds), The Upper Guinea Coast in Transnational Perspective. New York NY: Berghahn Books.

Schiller, N. G. and A. Çağlar (2009) 'Towards a comparative theory of locality in migration studies: migrant incorporation and city scale', Journal of Ethnic and Migration Studies 35 (2): 177-202.

Schlee, G. (1989) Identities on the Move: clanship and pastoralism in northern Kenya. Manchester: Manchester University Press.

Schramm, K. (2008) 'Leaving area studies behind: the challenge of diasporic connections in the field of African studies', African and Black Diaspora 1 (1): 1-12.

Shaw, R. (2002) Memories of the Slave Trade: ritual and the historical imagination in Sierra Leone. Chicago IL: University of Chicago Press.

Smith, M. P. (2003) 'Transnationalism, the state, and the extraterritorial citizen', Politics and Society 31 (4): 467-502.

Smith, M. P. and L. Guarnizo (eds) (1998) Transnationalism from Below. Piscataway NJ: Transaction.

Turton, D. (2003) Conceptualising Forced Migration. RSC Working Paper 12. Oxford: Refugee Studies Centre (RSC).

Turton, D. and T. Allen (1996) 'Introduction' in T. Allen (ed.), In Search of Cool Ground: war, flight and homecoming in northeast Africa. London: Africa World Press and James Currey.

UN DESA (2015) Trends in International Migrant Stock: the 2015 revision. New York NY: United Nations Department of Economic and Social Affairs (UN DESA).

Vertovec, S. (1999) 'Conceiving and researching transnationalism', Ethnic and Racial Studies 22 (2): 447-62.

Zeleza, P. T. (2005) 'Rewriting the African diaspora: beyond the Black Atlantic', African Affairs 104 (414): 35-68.

Zeleza, P. T. (2010) 'African diasporas: toward a global history', African Studies Review 53 (1): 1-19.

Zetter, R. (1991) 'Labelling refugees: forming and transforming a bureaucratic identity', Journal of Refugee Studies 4 (1): 36-62. 